American Journal of Pharmaceutical Education 2016; 80 (7) Article 115.

\title{
RESEARCH
}

\section{An Analysis of Community Pharmacy Shared Faculty Members' Contributions to Teaching, Service, and Scholarship}

\author{
Jennifer L. Bacci, PharmD, MPH, ${ }^{\text {a }}$ Tolu P. Akinwale, PharmD, ${ }^{\text {b }}$ Alex J. Adams, PharmD, MPH, ${ }^{c}$ \\ Melissa Somma McGivney, PharmD ${ }^{\mathrm{d}}$ \\ ${ }^{a}$ University of Washington School of Pharmacy, Seattle, Washington \\ ${ }^{\mathrm{b}}$ Walgreen Co., Deerfield, Illinois \\ ${ }^{\mathrm{c}}$ Idaho State Board of Pharmacy, Boise, Idaho \\ ${ }^{\mathrm{d}}$ University of Pittsburgh School of Pharmacy, Pittsburgh, Pennsylvania \\ Submitted June 29, 2015; accepted August 25, 2015; published September 25, 2016.
}

Objective. To identify community pharmacy shared faculty members across the United States and to describe their roles and responsibilities in terms of teaching, service, and scholarship.

Methods. This study was a mixed-methods analysis using surveys and key informant interviews.

Results. Twenty-two faculty members completed the survey; nine were interviewed. Their major roles and responsibilities included teaching in community-based and experiential learning courses, precepting students and/or residents, being actively involved in professional organizations, providing patient care while leading innovation, and disseminating findings through scholarship.

Conclusion. Community pharmacy shared faculty members contribute to their academic institutions and community pharmacy organizations by educating learners, providing direct patient care, and advancing community practice through innovation and service to the profession. Findings of this study can be used as a guide for academic institutions and community pharmacy organizations interested in partnering to develop a community pharmacy shared faculty position.

Keywords: pharmacy education, faculty, community pharmacy

\section{INTRODUCTION}

Community pharmacies are transforming from the building where patients receive their medications to destinations for health and wellness in peoples' neighborhoods. Reflecting this change, the scope of community pharmacists' services has expanded well beyond the provision of drug products and now includes medication management and reconciliation, educational and behavioral counseling, and preventive health care services, among others. Their roles have been further integrated as members of community-based primary care teams. ${ }^{1}$

Continuing to build on the momentum of this transformation may require a consistent generation of highquality patient care practices and innovation. Community pharmacy shared faculty members are well positioned to grow patient care in the community setting, just as shared faculty members pioneered the growth of clinical pharmacy in hospitals from the 1970 s through the 1990 s. $^{2-5}$

Corresponding Author: Jennifer L. Bacci, University of Washington School of Pharmacy, 1959 NE Pacific St., Box 357630, Seattle, WA 98195-7630. Tel: 206-221-3372. Fax: 206-543-3835. E-mail: jbacci@uw.edu
These early clinical pharmacists made significant contributions to practice, pharmacy education, and scholarship. Their achievements paved the way for other clinical pharmacy positions that were funded not only by academia but also by practices and institutions. ${ }^{5}$

Similarly, community pharmacy shared faculty positions allow community pharmacy organizations to partner with academic institutions to implement and test innovative patient care models. ${ }^{4,6}$ Reports on experiences and models establishing community pharmacy shared faculty partnerships note that partnerships increased community partners' capacity to provide patient care and provided academic institutions with additional experiential education sites for their students. ${ }^{6,7}$ The growth of patient care opportunities in the community setting and benefits of these partnerships may continue to result in growth of the number of shared faculty positions with community partners. ${ }^{3}$

An evaluation of the landscape of community pharmacy shared faculty members and a more detailed understanding of their work is needed and could create opportunities for the development of more shared faculty positions nationally. Our team sought to fill this gap by identifying community pharmacy shared faculty 


\section{American Journal of Pharmaceutical Education 2016; 80 (7) Article 115.}

partnerships across the country and describing the faculty members' contributions to teaching, service, and scholarship using a mixed-methods analysis. Our goal was to provide an in-depth look at the structure, roles, and responsibilities of these faculty positions to serve as a springboard for academic institutions and community pharmacy partners interested in developing shared faculty positions. The objectives of this study were to: (1) identify community pharmacy shared faculty members across the United States; and (2) describe their roles and responsibilities in teaching, service, and scholarship.

\section{METHODS}

The deans of all schools and colleges of pharmacy in the United States were surveyed to identify community pharmacy shared faculty positions and the community pharmacy organizations with which their institutions partnered. The deans were invited to participate in an online survey via e-mail in January 2014. Qualtrics survey software (Qualtrics LLC, Provo, UT) was used for all surveys in this study. Up to two reminder e-mails were sent to nonresponding deans at approximately 2 -week intervals. After the third attempt, the survey link was sent to the chairs of the pharmacy practice department at nonresponding institutions. A link to the survey was included in each e-mail. The deans of nonresponding institutions were also approached and surveyed orally by a study investigator at the American Association of Colleges of Pharmacy's (AACP) 2014 Interim Meeting. Investigators did not provide deans or department chairs with a definition of a community pharmacy shared faculty member to assess how academic institutions were defining them. However, the research team did clarify that community pharmacy shared faculty members were not faculty members merely "moonlighting" in a community pharmacy.

The shared faculty members in community pharmacy identified by deans and department chairs were then invited to participate in a survey in March 2014. Survey questions were designed to elicit data on the structure of the shared faculty members' positions and the breadth and depth of their teaching, service, and scholarship responsibilities. The survey was developed to capture both categorical and numerical, discrete data. The research team defined service to include service to patients through practice as well as service to one's academic institution, profession, and community. Demographic data were also collected. The survey was piloted with two community pharmacy shared faculty members. Descriptive statistics, including measures of central tendencies, frequencies, and percentages, were calculated to describe participant responses to the survey. Medians were used as the measure of central tendency because the data were skewed. Faculty members' scholarly productivity was normalized by dividing the participants' total number of research studies or publications by the participants' total number of years in their position. All analyses were carried out using Stata, v13.1 (StataCorp LP, College Station, TX).

Key informant interviews were conducted to gain deeper insight into the roles and responsibilities of community pharmacy shared faculty positions. Faculty members who indicated they would be willing to participate in an interview and provided their contact information on the survey were recruited to be interviewed. Interviews were conducted using a semi-structured script developed based on the survey results. Questions were designed to elicit the participants' perceptions of their institution's definition of shared faculty members, the history of the partnership between the academic institution and the community pharmacy organization, the "value" added to their practice site and school, strategies for time management, and tools or support that would benefit community pharmacy shared faculty members.

The interviews were conducted telephonically in May 2014. They were audio recorded using GoToMeeting, v7.0.5 (Citrix, Fort Lauderdale, FL) and transcribed by the University of Pittsburgh Qualitative Data Analysis Program (QDAP). Data saturation was not assessed because of the limited number of potential interviewees. The transcripts underwent thematic analysis. Two investigators independently read and coded the transcripts. Meaningful sentences and phrases were labeled with codes. The investigators then met to discuss coding decisions and resolve coding misalignments. The investigators used Microsoft Word to code, using one codebook that underwent continual edits during the process. A senior investigative panel reviewed the transcripts for gaps, inconsistencies, or new interpretations to improve the validity of the analysis. The coded text was grouped into categories to identify major themes. The research team met to collectively agree on final themes. ${ }^{8,9}$ Corresponding quantitative and qualitative results were merged and are presented in the Results section to provide a detailed description of community pharmacy shared faculty members' roles and responsibilities in their academic institutions and community pharmacy organizations in teaching, service, and scholarship. This study was classified as exempt from review by the University of Pittsburgh Institutional Review Board.

\section{RESULTS}

The initial survey to identify community pharmacy shared faculty members across the country was completed by deans and department chairs at 104 schools of pharmacy (75\% response rate). Twenty-nine schools $(28 \%)$ 


\section{American Journal of Pharmaceutical Education 2016; 80 (7) Article 115.}

indicated having at least one community pharmacy shared faculty position. Two schools reported four community pharmacy shared faculty positions; four schools reported two positions; and 23 schools reported one position for a total of 39 community pharmacy shared faculty positions across the country. The majority of schools indicating they had community pharmacy shared faculty members were located in the Midwest or on the East Coast. Contact information was provided for 30 of these faculty members.

Twenty-two community pharmacy shared faculty members completed the survey $(73 \%$ response rate). The majority of the survey respondents had a PharmD (91\%), had completed postgraduate year 1 (PGY1) community pharmacy residencies (68\%), and held certificates in immunizations (77\%) and medication therapy management (MTM) (64\%) through the American Pharmacists Association (APhA). Table 1 contains additional demographic

Table 1. Demographic Data of Community Pharmacy Shared Faculty Survey Respondents $(\mathrm{n}=22)$

\begin{tabular}{lc}
\hline Characteristic & n (\%) \\
\hline Median no. years in practice (range) & $5(1-33)$ \\
Median no. years as community pharmacy $^{\mathrm{a}}$ & $3(1-20)$ \\
$\quad$ shared faculty member (range) & $\mathrm{a}$ \\
Education and Training & \\
PharmD & $20(91)$ \\
BSPharm & $2(9)$ \\
Masters (MBA, MPH, MS, etc) & $2(9)$ \\
PGY1 Community Residency & $15(68)$ \\
PGY1 Pharmacy Practice Residency & $2(9)$ \\
PGY2 Residency & $2(9)$ \\
Fellowship & $1(5)$ \\
Board Certifications & \\
BCPS & $6(27)$ \\
BCACP & $4(18)$ \\
Other Certificates and Certifications & \\
Immunization Training & $17(77)$ \\
APhA Delivering MTM Services Certificate & $14(64)$ \\
APhA The Pharmacist and Patient-Centered & $11(50)$ \\
Diabetes Care Certificate & \\
APhA Pharmacy Based Lipid Management & $5(23)$ \\
Certified Asthma Educator (CAE) & $2(9)$ \\
Certified Diabetes Educator (CDE) & $2(9)$ \\
Certification in Geriatric Pharmacy (CGP) & $1(5)$ \\
Other & $3(14)$ \\
\hline
\end{tabular}

${ }^{\mathrm{a}}$ Based on data from 21 participants

PharmD $=$ Doctor of Pharmacy; BSPharm $=$ Bachelor of Science in Pharmacy; MBA= Master of Business Administration; $\mathrm{MPH}=$ Master of Public Health; MS=Master of Science; PGY1= postgraduate year 1; PGY2 = postgraduate year 2; BCPS = Board Certified Pharmacotherapy Specialist; $\mathrm{BCACP}=$ Board Certified Ambulatory Care Pharmacist; $\mathrm{APhA}=$ American Pharmacists Association; $\mathrm{MTM}=$ medication therapy management

information. Nine shared faculty members were recruited to participate in key informant interviews.

Combined survey and interview results revealed the structure and definition of community pharmacy shared faculty positions varied. Most survey respondents' indicated an academic rank of assistant professor (82\%), with their salary source coming from the school of pharmacy (55\%). The most common time splits between academic institutions and practice sites were $50 \%$ school $/ 50 \%$ practice site (41\%), 40/60 (18\%), 20/80 (14\%), and 60/40 (14\%). Table 2 contains additional details about the structure of respondents' shared positions.

Faculty members described many definitions of shared faculty members during interviews, ranging from being solely defined by location, funding, or both. In some cases, faculty members were not aware of any definition. In most cases, faculty members expressed uncertainty of the formal definition. Participants' quotes regarding the definition of shared faculty members are displayed in Table 3.

Regardless of structure and definition, most respondents described how their positions were initiated through established relationships and with leadership support. In most cases, the shared faculty positions were created from long standing partnerships, successful community pharmacy residency experiences, and/or school leadership seeking quality community pharmacy experiences for students. Supporting comments are provided in Table 3.

Interviewed faculty members shared that they perceived they contributed value to their organizations by teaching in both the academic and practice settings. Their

Table 2. Demographic Data of Structure of Survey Respondents' Shared Faculty Positions $(n=22)$

\begin{tabular}{lc}
\hline Characteristic & n (\%) \\
\hline Academic Title & \\
Assistant Professor & $18(82)$ \\
Associate Professor & $3(14)$ \\
Professor & $1(5)$ \\
Non-tenured Track & \\
Community Pharmacy Practice & \\
Setting & $18(86)$ \\
Supermarket & $8(36)$ \\
Traditional Chain & $5(23)$ \\
Independent & $3(14)$ \\
Mass Merchant & $2(9)$ \\
Other & $4(18)$ \\
Source of Salary & \\
School of Pharmacy & $12(55)$ \\
Community Pharmacy & $3(14)$ \\
Both & $7(32)$ \\
\hline aased on data from 21 participants &
\end{tabular}




\section{American Journal of Pharmaceutical Education 2016; 80 (7) Article 115.}

Table 3. Key Informants' Quotes on the Definition of Shared Faculty; Partnership Origins; Classroom, Experiential Learning, and Practice Responsibilities; and, Support for Shared Faculty Members

Quotes on the definition of shared faculty members

Quotes on the origin of the school and community pharmacy partnership

Quotes on faculty members' classroom responsibilities

Quotes on faculty members' experiential learning responsibilities

Quotes on faculty members' practice responsibilities
"... shared faculty are individuals who have both a clinical practice as well as responsibilities at the College of Pharmacy and there's shared funding in some capacity for that position."

"Shared faculty are individuals with split appointments between a practice site and the university."

“... any faculty that is either paid by two different sites... I would think that it's mainly based on where the salary comes from."

"I'm actually one of the few shared faculty in my institution, so there's not a clear definition."

"...my community practice site has been a long-standing partner of the school of pharmacy."

". . . at the end of [my community] residency the [college] dean and [the] vice president of operations [from the community pharmacy] said, 'Let's go to lunch. We'd like to have a discussion with you."”

“...I was under the understanding when I took the position that the practice site would be defined or created. . .based on my previous employment with my current practice site. I was able to stay there... a contract was developed between the college of pharmacy and the practice site..."

“... I get to expose students to community pharmacy at different points throughout the curriculum, as well as show them the value of the community pharmacist."

“...I'm taking over as course coordinator for our community pharmacy course...it's [a] really diverse group of topics. . from calculations to compounding, how to dispense medication[s], how to take prescription transfers, introduction to law, as well as evidence-based medicine."

"I lecture in a variety of courses... [patient] counseling, medication therapy management, [and] anything that affect[s] community [practice]...I also lecture in the therapeutics and pathophysiology sequences."

“...I'm the course coordinator for our introductory [community] practice experience. . .I oversee the content of the course as well as facilitate some online and in person discussions related to what the students are experiencing in community pharmacy."

“...we have [a] longitudinal [APPE] rotation. . . students apply to get in... they're with me for community clinical...they're working on MTM, screenings, direct patient care activities. . .management projects, and then they work with district managers. . They do presentations at the corporate office on ideas for services. So they get the basic community [experience]... and then an elective management, as well as the clinical community all in one."

"I have a student at my side. . basically 10 months out of the year."

"I am focused on generating new services that have sustainable business models that focus on non-dispensing operations. . I pilot it and get things up and rolling and then pass it off to other pharmacists who are within the pharmacy."

“... part of my role is to look for opportunities to expand our clinical services and think about how we can integrate those services into the workflow."

"I work closely with the actual manager of the store that I am based out of, but then also with the clinical coordinator of all the franchise stores to make sure that we're able to roll out the programs in the same manner in each store."

“...I'm responsible for immunization training, health testing training [within my community pharmacy organization..."

“...I lead a summer internship program...And then I lead a lot of the development and training classes for the pharmacists...to help promote the clinical initiatives that we have for our pharmacy." 


\section{American Journal of Pharmaceutical Education 2016; 80 (7) Article 115.}

Table 3. (Continued)

Quotes on support needed for community pharmacy shared faculty
". . I I think having a clear definition of what are those expectations, what [should] the shared faculty model look like, where do we want you to be, and what do we want you to be doing. . . Those are all things that I think maybe cannot be necessarily standardized but maybe would be nice to have some guidelines."

"I will say that my supervisors did make it a point to meet with me once a month when I first started, for about the first 6 months, to make sure that I was transitioning into the role well."

“...I had much more experience in being a community pharmacy practitioner, and providing MTM and clinical patient services that I did [on] the academic side. So, a strong academic orientation that allows share faculty to balance well is very important"

“. . I wouldn't say that I have a great network of people who actually have a job that kind of looks like mine. . so having maybe a little bit more of a network. .." major teaching responsibilities included course coordination, didactic lectures, and precepting, in addition to those typically expected of every faculty member such as small group facilitation. Additional details of these responsibilities and their volume during an academic year obtained from the survey are described in Table 4 . In the classroom setting, faculty members were coordinating or lecturing in courses that affected community practice such as selfcare and MTM. The interview participants' comments regarding the faculty members' classroom and experiential learning responsibilities are provided in Table 3.

Respondents also indicated that they had responsibilities within residency programs. Four respondents (18\%) were community residency directors and 10 respondents $(45 \%)$ were residency preceptors. Twenty-three percent of faculty members also served as ambulatory care preceptors for PGY1 pharmacy practice residencies.

Services provided by faculty respondents focused on leadership responsibilities at their school and particularly, state and national professional organizations (Figure 1). Respondents had served on a median of 1.5 school committees (range 1-5). They were members of a median of one state pharmacy association (range 1-2) and two national pharmacy associations (range 1-6). Nineteen respondents $(86 \%)$ were members of $\mathrm{APhA}$, and nine (41\%) were members of AACP. Other organizations with which the faculty members were involved included the American Society of Health-System Pharmacists, ACCP, National Community Pharmacists Association, American Association of Diabetes Educators, and Pharmacy Quality Alliance.

Sixteen $(73 \%)$ of the participating faculty members were also contributing to the community at large via service projects. Faculty members were participating in a median of two community service projects (range, 16). Their community service efforts varied but included precepting students through professional organizations, participating in community health fairs, assisting underserved populations in their communities, volunteering and fundraising, and participating in foundation work or medical missions.

Practice site time varied among faculty members. Five faculty members (23\%) spent $100 \%$ of their time on clinical responsibilities at their practice site, while 16 faculty members $(73 \%)$ spent at least $50 \%$ of their time on clinical responsibilities. Figure 2 depicts the clinical activities being performed by these community pharmacy shared faculty at their practice sites. Thirteen faculty members $(60 \%)$ were providing diabetes management services; eight (36\%) were providing hypertension management services; and seven $(32 \%)$ were providing hyperlipidemia management services. Asthma/COPD,

Table 4. Survey Respondents' Teaching Responsibilities Within Their Shared Position $(n=22)$

\begin{tabular}{lcc}
\hline Teaching Responsibility & $\begin{array}{c}\text { No. of Respondents with Teaching } \\
\text { Responsibility (\%) }\end{array}$ & $\begin{array}{c}\text { Volume During An Academic } \\
\text { Year, Median (Range) }\end{array}$ \\
\hline Course Coordination & $20(91)$ & $1(1-3)$ \\
Didactic Lectures & $20(91)$ & $9(1-35)$ \\
Precepting Advanced Pharmacy Practice & $20(91)$ & $10(5-40)$ \\
$\quad$ Experience (APPE) Students & $9(41)$ & $12(1-40)$ \\
Precepting Introductory Pharmacy Practice & & \\
$\quad$ Experience (IPPE) Students & & \\
\hline
\end{tabular}


American Journal of Pharmaceutical Education 2016; 80 (7) Article 115.

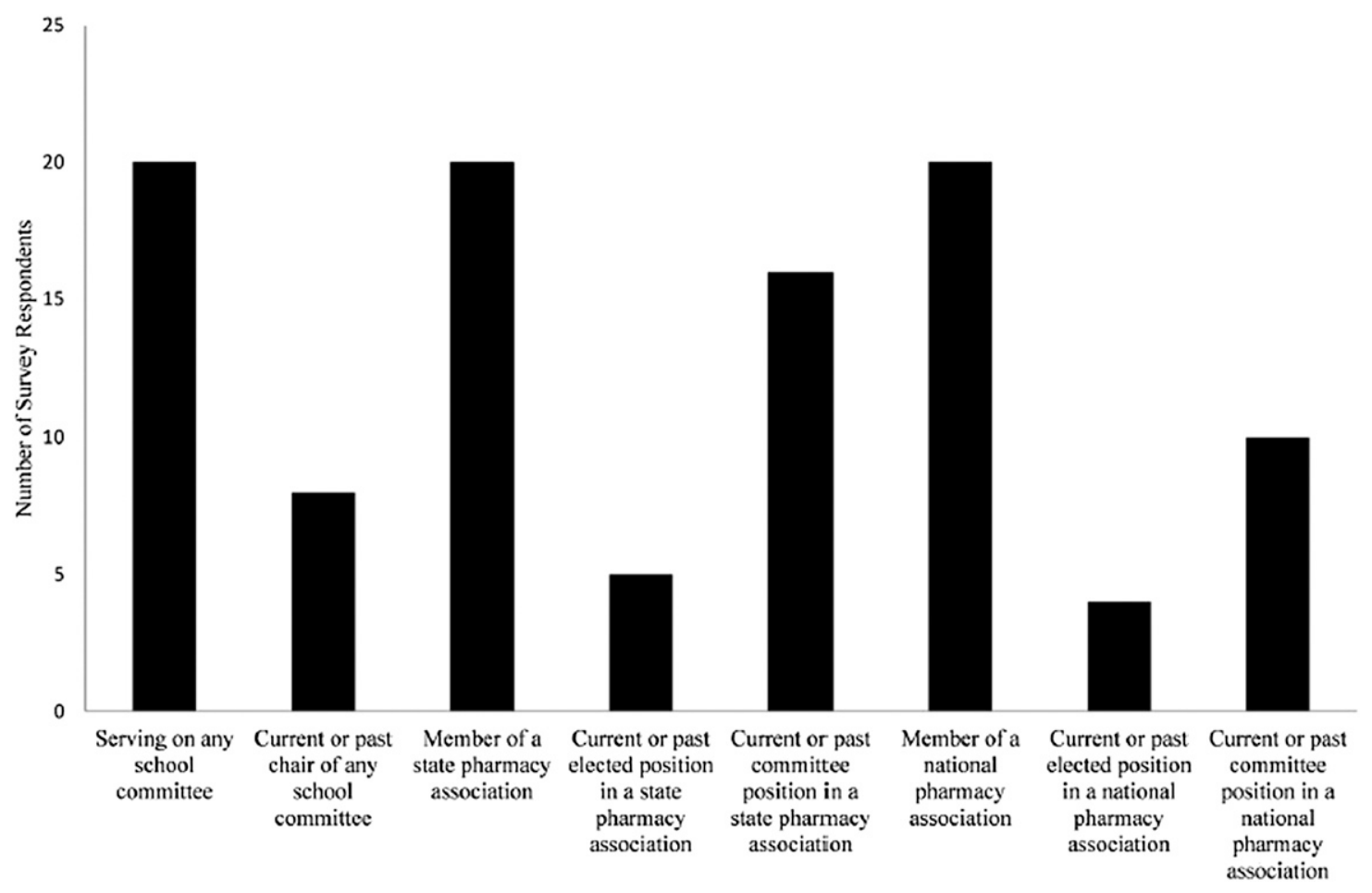

Figure 1. Community Pharmacy Shared Faculty Members' Service Responsibilities ( $n=22)$.

smoking cessation, weight management, rheumatoid arthritis, mental health, and human immunodeficiency virus (HIV) management programs were also being provided. Twenty-one faculty members (95\%) were providing adult immunizations; 10 (45\%) were providing travel vaccines; and $9(41 \%)$ were providing pediatric immunizations. The faculty members were performing these services at one or multiple community pharmacy locations.

Four faculty members (18\%) spent at least $50 \%$ of their time at their practice site on management activities. Management activities performed by the faculty members included organization-wide program development, development of policies and procedures, and pharmacist management and development. These shared faculty members emphasized their managerial roles in innovation, expanding clinical services, and implementation at their practice sites. Shared faculty members were also contributing to the development and implementation of training programs at their practice sites. Eight faculty members $(36 \%)$ had dispensing responsibilities ranging from $5 \%$ to $65 \%$ of their time at their practice sites. Interviewees' comments describing their responsibilities at practice sites are included in Table 3.

All survey respondents indicated they were involved in research (from $5 \%$ to $40 \%$ of their effort). Faculty members were producing, on average, 0.25 research studies per year as primary investigator, 0.6 research studies per year as coinvestigator, 0.5 peer-reviewed publications per year, and 0.5 nonpeer reviewed publications per year. The research expectations of community pharmacy shared faculty members varied. In interviews, some faculty members shared explicit publication and/or presentation goals, while others expressed that productivity is expected but without explicit benchmarks. Other faculty members had chosen to become involved in research out of personal interest and for their own scholarly growth. Moreover, some faculty members shared that scholarship expectations are tied to their residents' or students' successful completion of projects required for accreditation or graduation. Eleven respondents (50\%) served as resident research project mentors while 10 (45\%) served as student research project mentors. During interviews, faculty members said it was critical for academic institution and community partner to clarify scholarship expectations.

Most of the scholarship produced by shared faculty members was from the evaluation of patient care services at their practice sites. Yet, some identified research as their biggest opportunity for growth (detailed by the remarks provided in Table 3). As a result, faculty members expressed a strong desire for additional training and support to strengthen their practice-based research skills.

Interview participants expressed facing challenges specific to their academic institution and community pharmacy organization such as figuring out office space, parking, and mileage reimbursement when traveling between the community pharmacy and the school. Other challenges 


\section{American Journal of Pharmaceutical Education 2016; 80 (7) Article 115.}

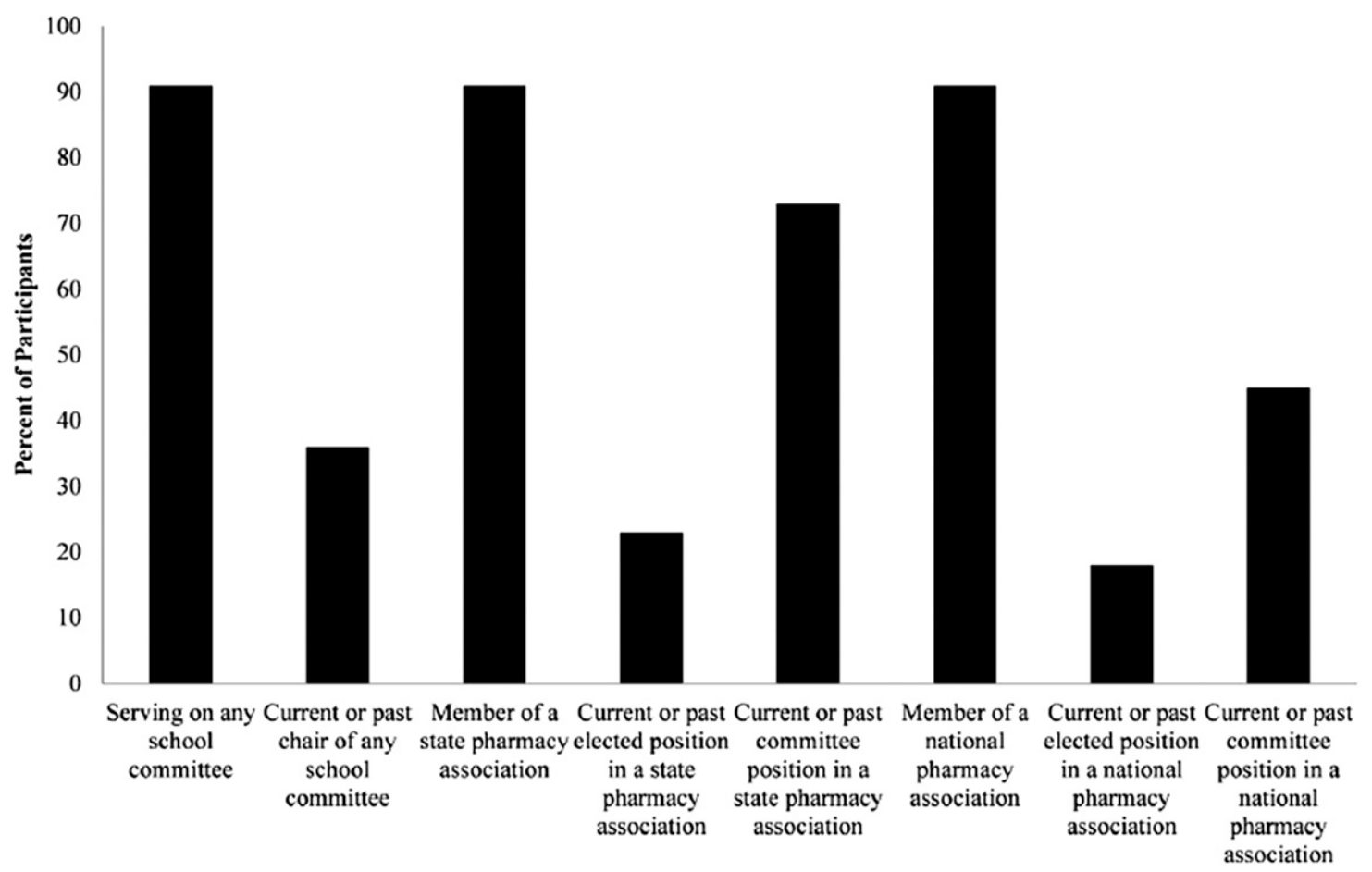

Figure 2. Clinical Activities Performed by Community Pharmacy Shared Faculty at their Practice Sites $(n=22)$.

were more global such as balancing time at their sites and integrating scholarship with their many roles and responsibilities. They felt these challenges needed to be addressed for them and others to be effective in their roles.

Participants identified ideas for supporting shared faculty members such as transparency, open communication, and aligned expectations for the shared faculty position among the school administration, community pharmacy leadership, and themselves. Other opportunities for support included providing shared faculty members with a strong orientation on strategies for balancing responsibilities and establishing a network of community pharmacy shared faculty members. Supporting comments are provided in Table 3.

\section{DISCUSSION}

This study provides a deeper look into the roles and responsibilities of community pharmacy shared faculty members across the country. These faculty members contribute value to their academic institutions and community pharmacy organizations through the core tenets of academia. They teach in community-based and experiential learning courses, precept pharmacy residents and students, and work to advance community pharmacy through involvement and leadership in multiple state and national professional organizations. They also provide patient care services, innovate within their practices, and disseminate findings via scholarship.
A key finding of this study is the lack of consensus on the definition of a shared faculty member. Participants' varied definitions of shared faculty members were based on location, funding, or both. Shared faculty positions are described in pharmacy literature as arrangements between a pharmacy practice and a school of pharmacy where either one party or both provide salary support. ${ }^{6}$ Dental practice literature also defines shared faculty members as individuals with dual appointments by a practice and an academic institution. ${ }^{10}$ We contend that shared faculty members should be defined as having shared salary support from the academic institution and practice site. This definition differs from typical clinical-track faculty members whose salaries are fully supported by the academic institution even though they have a practice at a partner organization. This proposed definition is important because it can set clearer goals for faculty members and their colleagues. A clearer definition can also raise awareness of the role and value of shared faculty positions. Finally, the definition may have implications for practice issues, such as billing, and related items.

Pharmacists' credentials and organizations' credentialing processes also have implications regarding payment for services and other practice-related issues. ${ }^{11}$ Respondents had a variety of post licensure credentials including additional degrees, residency and/or fellowship training, board certification, and other certificates and certifications. Following the rationale for credentialing 


\section{American Journal of Pharmaceutical Education 2016; 80 (7) Article 115.}

processes, community pharmacy shared faculty members should have the appropriate credentials to support their scope of practice and patient care responsibilities. ${ }^{11}$ Appropriate credentials should be determined by the academic institution and community partner based on the work faculty members will be performing.

Additional findings potentially unique to shared faculty members who practice in the community setting are their high level of involvement in practice innovation, service, and leadership through professional organizations and community projects. Participants described their efforts in generating new patient care opportunities with sustainable business models. This aligns with the rapid evolution of opportunities to provide and be reimbursed for patient care services in the community setting. Research also describes shared faculty members' role in experimenting with new patient care models, thereby providing an opportunity to test these innovative models before implementation of company-wide programs that advance population health. ${ }^{6,7}$

A new finding is the level of engagement of community pharmacy shared faculty members in professional organizations and community service projects. Collaboration with professional organizations and participation in service projects may allow these faculty members to become further rooted in the communities in which they are practicing, assist in their charge to advance patient care models, and contribute to a growing trend in public health in partnering with other health care and community development sectors to improve population health and wellbeing. ${ }^{12}$ This level of engagement in the community may also help figuratively break down the walls of a pharmacy and allow the community greater access to care.

Faculty members shared that they find research and time balance the most challenging aspects of their positions. This finding is consistent with existing literature on research productivity and time balance among junior faculty and practice-based faculty members, regardless of practice setting or expertise. ${ }^{13,14}$ Faculty members perceived research activities as being more important than teaching or service with respect to promotion. Yet, they felt least confident in their ability to fulfill the researchrelated expectations of their positions. ${ }^{13,15}$ Addressing this incongruence is critical to retaining faculty members. ${ }^{16,17}$ This issue is further compounded by the effect of increasing scholarship demands on clinical practice faculty members' abilities to balance all of their responsibilities. Time balance is a barrier to scholarship among medical, dental, nursing, and pharmacy practice faculty members. ${ }^{18}$

Mentoring programs are commonly used to provide research support to junior or clinical faculty members. Many faculty development and mentoring program structures are published. ${ }^{19-23}$ Participants in our study expressed a desire for a learning community with other shared community pharmacy faculty members to foster professional development and growth. ${ }^{24,25}$ They wanted a forum to share ideas with faculty members facing similar challenges and learn from each other's successes. Pharmacy faculty members' current opportunities for professional development and networking outside of their academic institutions are offered through the professional organizations. Examples include the ACCP Research Institute, AACP Academic Leadership Fellows Program, and the National Association of Chain Drug Stores (NACDS) Foundation Faculty Scholars Program. ${ }^{26-28}$

Overall, the success of community pharmacy shared faculty members is dependent on the strength of the relationship between the academic institution and community pharmacy organization. These faculty members are charged with stimulating innovation in community-based patient care. This is an endeavor that requires open, transparent communication and support from all stakeholders, who include the shared faculty member and community pharmacy organization. School leaders are also integral stakeholders. Study participants were most successful when their department chair or dean was actively engaged in building and maintaining the relationship with the community partner. Engaging the right individuals and committing the time to build and maintain a relationship are critical first steps for any academic institution and community pharmacy organization looking to partner to form a shared faculty position.

One limitation of this study is that the described practice responsibilities of the shared faculty members were limited by their scope of practice; however, most respondents were practicing at the top of their abilities, as defined by the law in the state in which they were practicing. The survey response rates are another potential limitation of this study. Lastly, we did not include deans, department chairs, or community partners in this analysis. Their perspectives should be included in future evaluations of community pharmacy shared faculty members.

Future work should engage all stakeholders within the profession to identify optimal strategies for supporting shared faculty members, given the importance of their work and challenges of a shared position. Stakeholders should develop promotion and tenure guidelines that match the work of the community pharmacy shared faculty members and the goals of academic and community pharmacy partners and identify the best possible avenues for disseminating community pharmacy shared faculty members' scholarship to its target audience: other practicing community pharmacists. 


\section{American Journal of Pharmaceutical Education 2016; 80 (7) Article 115.}

\section{CONCLUSION}

This study provides an in-depth look at the breadth of shared community pharmacy faculty members' contributions to teaching, service, and scholarship. Commonalities among all participating shared faculty members include teaching in community-based and experiential coursework, precepting residents and/or students, and being actively involved in professional organizations. Shared faculty members provide a variety of patient care services that support scholarship through generation of innovative, sustainable patient care models. Structures of shared faculty positions differ among academic institutions and their community pharmacy partners. Findings of this study can be used as a guide for academic institutions and community pharmacy organizations interested in partnering to develop a community pharmacy shared faculty position.

\section{ACKNOWLEDGMENTS}

Transcription was supported by the NACDS Foundation. The authors would like to acknowledge Kim Coley for her assistance in preparing this manuscript. At the time research was conducted, Jennifer Bacci was a community pharmacy research fellow at the University of Pittsburgh School of Pharmacy; Tolu Akinwale was an executive fellow at NACDS Foundation; and Alex Adams was vice president of Research Programs at NACDS Foundation. The views expressed in this manuscript are those of the authors alone, and do not necessarily reflect those of their respective employers.

\section{REFERENCES}

1. Avalere Health LLC. Exploring pharmacists' role in a changing healthcare environment. http://avalere.com/expertise/life-sciences/ insights/exploring-pharmacists-role-in-a-changing-healthcareenvironment. 2014. Accessed May 11, 2015.

2. American College of Clinical Pharmacy. The definition of clinical pharmacy. Pharmacother. 2008;28(6):816-817.

3. Littlefield LC, Haines ST, Harralson AF, et al. Academic pharmacy's role in advancing practice and assuring quality experiential education: report of the 2003-2004 Professional Affairs Committee. Am J Pharm Educ. 2004;68(3):S8.

4. Smith MA. Pharmacists and the primary care workforce. Ann Pharmacother. 2012;46(11):1568-1571.

5. Birtcher KK, Corbett SM, Pass SE, et al. Symposium on roles of and cooperation between academic- and practice-based pharmacy clinicians. Am J Health-Syst Pharm. 2010;67(3):231-238.

6. Reutzel TJ, Hogan M, Kazerooni PV. Development of a patientbased practice model in community pharmacy practice: academicpractice interface. Am J Pharm Educ. 1999;63(2):119-126.

7. Pattin A, Szyskowski J. The development of a patient care center in a supermarket chain pharmacy. J Pharm Pract. 2012;26(1):32-35. 8. Kahlke RM. Generic qualitative approaches: pitfalls and benefits of methodological mixology. Int J Qual Meth. 2014;13(1):37-52.

9. Krueger R. Focus Groups: A Practice Guide for Applied Research. Thousand Oaks, CA: Sage Publications Ltd.; 2000.
10. Hamamoto DT, Farrar SK, Caplan DJ, Lanphier TF, Panza JC, Ritter AV. Use of shared faculty in US and Canadian dental school. $J$ Dent Educ. 2013;77(3):264-275.

11. Council on Credentialing in Pharmacy. Credentialing and privileging of pharmacists: a resource paper from the Council on Credentialing in Pharmacy. Am J Health-Syst Pharm. 2014;71 (21):1891-1900.

12. Braunstein S, Lavizzo-Mourey R. How the health and community development sectors are combining forces to improve health and well-being. Health Aff. 2011;30(11):2042-2051.

13. Robles JR, Youmans SL, Byrd DC, Polk RE. Perceived barriers to scholarship and research among pharmacy practice faculty: survey report from the AACP Scholarship/Research Faculty Development Task Force. Am J Pharm Educ. 2009;73(1):Article 17.

14. Nutescu EA, Engle JP, Bathija S, et al. Balance of academic responsibilities of clinical track pharmacy faculty in the United States: a survey of select American College of Clinical Pharmacy Practice and Research Network members. Pharmacother. 2014;34 (12):1239-1249.

15. Lee KC, El-Ibiary SY, Hudmon KS. Evaluation of research training and productivity among junior pharmacy practice faculty in the United States. J Pharm Pract. 2010;23(6):553-559.

16. Conklin MH, Desselle SP. Job turnover intentions among pharmacy faculty. Am J Pharm Educ. 2007;71(4):Article 62. 17. Fuller K, Maniscalco-Feichtl M, Droege M. The role of the mentor in retaining junior faculty members. Am J Pharm Educ. 2008;72(2):Article 41.

18. Smesny AL, Williams JS, Brazeau GA, Weber RJ, Matthews HW, Das SK. Barriers to scholarship in dentistry, medicine, nursing, and pharmacy practice faculty. Am J Pharm Educ. 2007;71(5):Article 91. 19. Brock TP, Assemi M, Corelli RL, et al. A nontraditional faculty development initiative using a social media platform. Am J Pharm Educ. 2014;78(5):Article 105

20. Haines SL, Popovich NG. Engaging external senior faculty members as faculty mentors. Am J Pharm Educ. 2014;78(5):Article 101.

21. Jackevicius CA, Le J, Nazer L, Hess K, Wang J, Law AV. A formal mentorship program for faculty development. Am J Pharm Educ. 2014;78(5):Article 100

22. Lancaster JW, Stein SM, MacLean LG, Van Amburgh J, Persky AM. Faculty development program models to advance teaching and learning within health science programs. Am J Pharm Educ. 2014;78 (5): Article 99.

23. Boyce EG, Burkiewicz JS, Haase MR, et al. Essential components of a faculty development programs for pharmacy practice faculty. Pharmacother. 2008;28(10):245e-268e.

24. Glowacki-Dudka MG, Brown MP. Professional development through faculty learning communities. New Horiz Adult Educ Hum Resour Dev. 2007;21(Issue 1-2):29-39.

25. Sicat BL, Kreutzer KK, Gary J, et al. A collaboration among health sciences schools to enhance faculty development in teaching. Am J Pharm Educ. 2014;78(5):102.

26. Investigator and Scholarship Development. American College of Clinical Pharmacy Research Institute. http://www.accpri.org/ investigator/. Accessed May 25, 2015.

27. Academic Leadership Fellows Program. American Association of Colleges of Pharmacy. http://www.aacp.org/career/leadership/ Pages/default.aspx. Accessed May 25, 2015.

28. Education. National Association of Chain Drug Stores Foundation. http://www.nacdsfoundation.org/priorities/education/. Accessed May 25, 2015. 